DOI 10. 18307/2017. 0606

(c) 2017 by Journal of Lake Sciences

\title{
沙基和浮床培养方式种植水芹对人工湿地冬季水质净化能力的 对比
}

\author{
左 杰 ${ }^{1}$, 季 军 $^{2}$, 汪鹏合 ${ }^{1}$, 张 惠 $^{1}$, 张文娟 ${ }^{1}$, 赵德华 ${ }^{1 * *}$, 安树青 ${ }^{1,3}$ \\ (1: 南京大学生命科学学院, 南京 210046) \\ ( 2 : 洪泽县清盈尾水湿地管理有限公司, 淮安 223001) \\ (3: 南京大学常熟生态研究院, 常熟 215500)
}

\begin{abstract}
摘 要: 针对人工湿地冬季净化能力不足以及不同湿地植物种植方式可能影响其净化效果的湿地构建问题, 通过小试实 验,研究了沙基法和浮床法种植水芹 (Oenanthe javanica (Bl.) DC.) 对冬季人工湿地净化富营养水体效果的影响. 在整个 冬季, 4 个实验周期中, 处理期间总磷 (TP) 和总氮 (TN) 去除率表现出显著差异: 对照组 (CK)、沙基种植组和浮床种植组 4 个周期对 TP 的去除率平均值为 $20.17 \% \pm 19.23 \% 、 59.60 \% \pm 7.54 \%$ 和 $45.44 \% \pm 29.22 \%$; 对 TN 的去除率平均值依次为: $29.83 \% \pm 19.65 \% 、 64.89 \% \pm 23.01 \%$ 和 $60.50 \% \pm 25.86 \%$. 与 CK 组相比, 冬季种植水芹可显著提高湿地对 TP 和 TN 的去除 率; 与浮床种植方式相比, 沙基种植方式的 TP 和 TN 去除率略有提高. 而对于 COD 的去除率, 沙基种植组周期间波动较 大 $(-27.5 \% \sim 52.92 \%)$, 浮床种植组组周期间更为平稳 ( $10.83 \% \sim 40.42 \%)$, 浮床种植组在全部 4 个周期的平均去除率 $(23.13 \% \pm 14.41 \%)$ 略高于沙基种植组 $(19.38 \% \pm 35.38 \%) .2$ 种种植方式下, 水芹均可安全适应冬季温带气候; 与沙基种 植法相比, 浮床种植方式更有利于植物总生物量的增加, 特别是根系生物量的增加; 相对于浮床种植, 传统的沙基种植法 能使水芹根系在温带冬季大部分时间内保持较高的活力和泌氧能力. 因此, 考虑到建设成本, 在浅水区域可优选传统的 沙基(或底泥)种植方式; 在深水区域, 使用浮床种植的方式, 也能保证耐寒水生植物安全度过冬季和保持较高的净化 能力.
\end{abstract}

关键词: 人工湿地; 水芹; 种植方式; 根系活力;营养物去除;水质净化;沙基法;浮床法

\section{Comparison of Oenanthe javanica's winter purification ability in constructed wetlands under sand and floating-bed cultures}

\author{
ZUO Jie $^{1}$, JI Jun ${ }^{2}$, WANG Penghe ${ }^{1}$, ZHANG Hui ${ }^{1}$, ZHANG Wenjuan ${ }^{1}$, ZHAO Dehua $^{1 * *}$ \& AN Shuqing ${ }^{1,3}$ \\ (1: School of Life Science, Nanjing University, Nanjing 210046, P.R.China) \\ (2: Qingying Tail Water Wetland Management Limited Company of Hongze County, Huaian 223001, P.R.China) \\ (3: Nanjing University Ecology Research Institute of Changshu, Changshu 215500, P.R.China)
}

Abstract : To improve purification ability of wetland in cold winter and reveal the impact of culture methods of wetland plants, a pilot-scale experiment was conducted to compare the performance of Oenanthe javanica using two culture methods, i.e. sand culture and floating-bed culture, in the purification of polluted water during winter. There existed significant different removal efficiency of total phosphorous ( TP) and total nitrogen ( TN) between various treatments. In the four studied batches, control check ( CK), sand culture and floating-bed culture showed an average of $20.17 \% \pm 19.23 \%, 59.60 \% \pm 7.54 \%$ and $45.44 \% \pm 29.22 \%$ TP removal efficiency, and an average of $29.83 \% \pm 19.65 \%, 64.89 \% \pm 23.01 \%$ and $60.50 \% \pm 25.86 \%$ TN removal efficiency, respectively. Compared with CK, the results showed that the plantation of Oenanthe javanica could significantly improve TP and TN removal efficiency in cold winter. Compared with floating-bed culture, sand culture had slightly higher removal ability for both TP and TN. But

* 国家水体污染控制与治理科技重大专项 (2014ZX07204-002) 和中央高校基本科研业务费专项资金项目 (14380019) 联合资助. $2016-12-24$ 收稿; $2017-02-15$ 收修改稿. 左杰 (1989 ) , 女, 硕士研究生; E-mail: zuojie_cyan@126.com.

** 通信作者;E-mail: dhzhao@ nju.edu.cn. 
for chemical oxygen demand (COD), the removal efficiency of CK and sand culture varied much between batches. Compared with sand culture $(-27.5 \%-52.92 \%)$, floating-bed culture showed a slightly higher and more stable COD removal efficient the four studied batches $(10.83 \%-40.42 \%)$. Oenanthe javanica in both sand culture and floating-bed culture survived temperate winter. Floating-bed culture performed significant higher total plant and root dry biomass than sand culture, while sand culture generally had significant higher root activity and root secretion than floating-bed culture. Therefore, considering the engineering costs, the traditional sand (or sediment) culture method is recommended at the shallow water areas where Oenanthe javanica can survive using either sand culture or floating-bed culture. For the deep water areas where Oenanthe javanica can't survive using sand culture, we can use floating-bed culture which can also perform relative high purification ability and make Oenanthe javanica survive in the temperate winter.

Keywords: Constructed wetland; Oenanthe javanica; culture methods; root activity; nutrients removal; water purification; sand culture; floating-bed culture

水生植物浮床起源于一项无土栽培技术,近年来被应用到受损或污染水体修复与治理领域 ${ }^{[1]}$. 通过水 生植物的直接吸收同化作用、根系生物膜微生物作用和根系向水体释放氧和有机质等方式进行或参与污染 物的去除 ${ }^{[2-4]}$. 相对于传统的基质栽培法, 大多数的浮床植物生长在水体表面, 根系直接与水体接触, 植物生 长环境存在显著差异 ${ }^{[5]}$,这种差异会同时影响水生植物的生长状况和水质净化效果 ${ }^{[6]}$. 当前,有关浮床优缺 点的定性描述及其在水生态工程的应用与研究很多, 但是, 相关方面主要集中在浮床水生植物筛选 ${ }^{[7-9]}$ 、浮 床对水生态系统的影响 ${ }^{[10]}$ 、高效基质一浮床复合体系构建 ${ }^{[11]}$ 和相关工艺改进 ${ }^{[12]}$ 等方面, 对于浮床的特征 小生境对水生植物生长和水质净化影响方面的研究却相对薄弱, 特别是对于我国北方冬季, 传统基质栽培 法和浮床栽培法对水生植物生长和水质净化影响对照研究方面尚未见报道.

本研究以耐寒水生植物水芹 (Oenanthe javanica) 为供试材料, 分别采用沙基种植法和浮床种植法, 研究 2 种栽培条件下, 水生植物在冬季期间的生长状况及其水质净化能力, 以期为水生态工程规划设计和工艺选 择,以及浮床技术在我国北方的推广应用提供理论依据.

\section{1 材料与方法}

\section{1 实验装置与材料}

实验地点位于江苏省淮安市洪泽县朱坝镇大魏村的野外实验基地. 实验在 9 个聚乙烯塑料桶中进行 (规格: $190 \mathrm{~cm} \times 110 \mathrm{~cm} \times 45 \mathrm{~cm}$, 图 1), 在每个桶底放置 $10 \mathrm{~cm}$ 厚沙子 (来自洪泽湖底, 细度模数为 3.1 3.7) 作为基质模拟人工湿地, 浮床选择 HCFC 500 型生态浮床 (规格: $50 \mathrm{~cm} \times 50 \mathrm{~cm}$, 每板浮床包含 9 个花篮孔). 实验用水取自基地附近池塘, 水质条件如下: COD $15 \mathrm{mg} / \mathrm{L}$, 总磷( TP ) $0.5 \mathrm{mg} / \mathrm{L}$, 硝态氮 $\left(\mathrm{NO}_{3}^{-}-\mathrm{N}\right) 0.1 \mathrm{mg} / \mathrm{L}$, 铵态氮 $\left(\mathrm{NH}_{4}^{+}-\mathrm{N}\right) 0.3 \mathrm{mg} / \mathrm{L}$, 通过人工添加 $\mathrm{KNO}_{3} 、\left(\mathrm{NH}_{4}\right)_{2} \mathrm{SO}_{4}$ 、葡萄糖, 获得富营养化实验用水: $\mathrm{COD} 80 \mathrm{mg} / \mathrm{L}$, $\mathrm{TP} 10 \mathrm{mg} / \mathrm{L}, \mathrm{NO}_{3}^{-}-\mathrm{N} 5 \mathrm{mg} / \mathrm{L}, \mathrm{NH}_{4}^{+}-\mathrm{N} 10 \mathrm{mg} / \mathrm{L}$. 整个实验期间保持水深 $15 \mathrm{~cm}$. 选取长势均一、株高 $30 \mathrm{~cm}$ 的水芹 幼苗, 剪掉枯黄叶片并用软毛刷清洗根部. 于 2015 年 12 月 10 日进行水芹移栽, 预培养 $14 \mathrm{~d}$ 后进行处理.

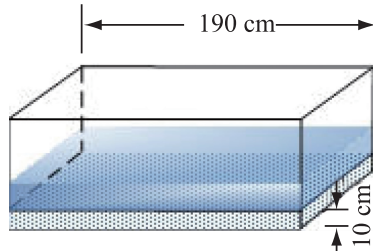

空白组

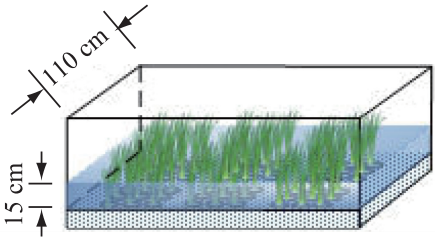

沙基种植组

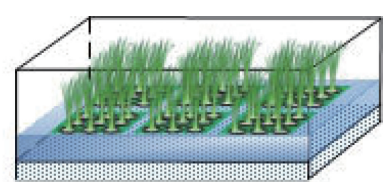

浮床种植组

图 1 小试实验装置示意

Fig.1 Diagram of the pilot scale test device

\section{2 实验设计}

实验设 3 个处理: 对照组 (CK), 不种植物且不加浮床; 沙基种植组, 水芹密度为 $190 \pm 5$ 株/缸; 浮床种植 组, 每缸放置 6 块浮床, 水芹密度为 $190 \pm 5$ 株/缸. 每个处理设置 3 次重复. 为降低干扰和后续取样方便, 沙 
基种植组的植物种植方式采用先将植物放置在花篮中 (与浮床种植组相同的花篮), 然后连同花篮一起埋人 沙中的种植方式. 实验采用周期性添加化学试剂的运行方式, 系统共运行 4 个周期, 每个周期开始前, 根据 实测每缸水体营养物质浓度, 计算和添加 $\mathrm{KNO}_{3} 、 \mathrm{KH}_{2} \mathrm{PO}_{4} 、\left(\mathrm{NH}_{4}\right)_{2} \mathrm{SO}_{4}$ 和葡萄糖, 使得每个缸内水质浓度 ( $\mathrm{COD} 80 \mathrm{mg} / \mathrm{L}, \mathrm{TP} 10 \mathrm{mg} / \mathrm{L}, \mathrm{NO}_{3}^{-}-\mathrm{N} 5 \mathrm{mg} / \mathrm{L}, \mathrm{NH}_{4}^{+}-\mathrm{N} 10 \mathrm{mg} / \mathrm{L}$ ) 接近于实验初始时的浓度(最终以实测数据为 准计算各个周期的去除率).

\section{3 采样与测定}

依据水芹冬季不同发育阶段理论, 设定实验时间. 实验进行 $77 \mathrm{~d}$, 共 5 次采样. 设定时间节点为开始处 理前 2015 年 12 月 24 日及 2016 年 1 月 4 日、 1 月 18 日、 2 月 21 日和 3 月 9 日. 2016 年 1 月 18 日测定水芹冬 季调落期的生长状况及人工湿地运行情况, 2016 年 1 月 19 日至 3 月 9 日为水芹温带气候条件下人工湿地 的运行情况. 采集水样和植物样本, 采样时间为上午 9:00. 采样时用 $250 \mathrm{ml}$ 采样瓶, 通过塑料桶底部的出水 管采集水样. 现场进行水质化学指标的检测工作,检测方法依据美国环境保护局 (USEPA) 标准:COD 采用 消解比色法; TN 浓度采用过硫酸盐氧化法; TP 浓度采用抗坏血酸法; 利用 YSI 6820U2 多参数水质分析仪检 测水体叶绿素 a 浓度; 水体温度采用 HOBO 防水型温度光照记录仪 (型号: UA-002-64) 置于水体中测得, 每 隔 15 min 记录 1 次数据, 每天记录 96 次, 取当天所有水体温度平均数进行分析.

在实验开始前和每个周期实验结束后, 对沙基种植组和浮床种植组进行植物样本采集: 每个处理选择 长势均一的植物样本, 采取 2 个花篮的样本. 用直尺测量出其地上部分高度、地下部分长度. 测完后, 用粗滤 纸把沉水植物水分吸干, 称取鲜重. 之后, 将装在信封中的植物放于烘箱, 先用 $110^{\circ} \mathrm{C}$ 杀青 $15 \mathrm{~min}$, 然后在 $75 \sim 80^{\circ} \mathrm{C}$ 烘干 $48 \mathrm{~h}$, 测定干重 ${ }^{[13]}$. 根系活力采用 TTC 法测定 ${ }^{[14]}$. 根系泌氧采用檬酸钛比色法测定 ${ }^{[15]}$.

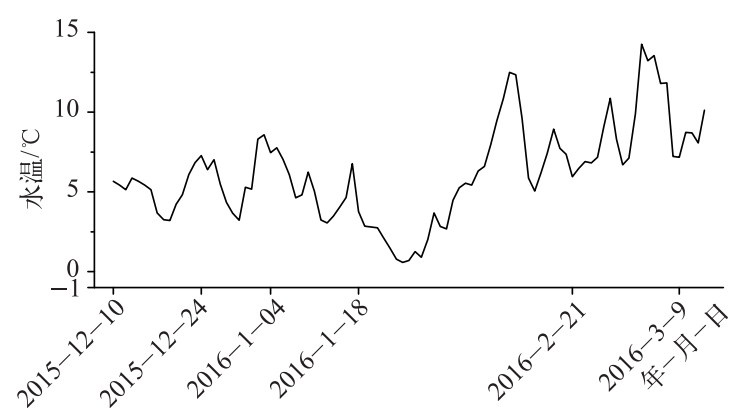

图 2 实验期水温变化动态

Fig. 2 The water temperature dynamic in the whole studied period

\section{4 实验运行条件}

实验时间为 2015 年 12 月 24 日- 2016 年 3 月 9 日, 2015 年 12 月 10 日- 12 月 23 日为预培养 时间. 第 I 周期 $(2015$ 年 12 月 24 日- 2016 年 1 月 3 日), 水体温度在 $3.23 \sim 8.58^{\circ} \mathrm{C}$ 之间波动; 第 II 周期( 2016 年 1 月 4 日 -1 月 17 日), 水体温度在 $2.74 \sim 6.76^{\circ} \mathrm{C}$ 之间, 有连续 $4 \mathrm{~d}$ 温度小于 $3^{\circ} \mathrm{C}$, 在 $2.10 \sim 2.84^{\circ} \mathrm{C}$ 之间; 第 III 周期 ( 2016 年 1 月 18 日一 2 月 20 日), 温度在 $0.58 \sim 12.50^{\circ} \mathrm{C}$ 范围内波动; 第 $\mathrm{IV}$ 周期 $(2016$ 年 2 月 21 日 -3 月 9 日) 平均温度 在 $6.70 \sim 14.26^{\circ} \mathrm{C}$ 之间 (图 2). 水体温度出现一个 持续 $5 \mathrm{~d}(2$ 月 28 日 -3 月 3 日) 平均温度为 $12.94^{\circ} \mathrm{C}$ 的小幅回升. 结果表明, 本实验经历了温

带冬季最低温和第二年开始升温的初始阶段.

\section{5 数据处理}

数据分析使用 Office Excel 2010 软件、单因素方差分析和独立样本 $t$ 检验采用 SPSS 19.0 软件, 装置图由 Office Visio 2013 绘制, 图表绘制工作由 Sigmaplot 12.5 和 Origin 9.1 软件完成.

\section{2 结果与分析}

\section{1 水体污染物去除率}

各处理组对 COD 的去除率表现为,在第I周期, 沙基种植组和浮床种植组对 COD 去除率分别达 $39.17 \%$ 和 $40.42 \%$, 而 CK 组为 $-21.3 \%$; 第周期, 沙基种植组仍然保持较高去除率 $(52.9 \%$ ), 而浮床种植组较 CK 组略有 降低; 第而周期, 沙基种植组迅速降低 ( $-27.5 \%$ ), 而浮床种植组仍然保持一定的 COD 去除能力 (10.83\%); 第 IV 周期, 沙基种植组和浮床种植组均略低于 CK 组 (图 3). 对 TP 的去除表现为, 第II周期和第IV 周期沙基种植组 和浮床种植组去除率均显著高于 $\mathrm{CK}(P=3.54 \mathrm{E}-4 \sim 0.003)$, 沙基种植组处理在第 I III和IV 周期表现略好于浮床 种植组, 而在第吕周期表现略差于浮床种植组, 4 个周期, 沙基种植组和浮床种植组的 TP 去除率平均值分别为 
59.6\% 和 45.4\%. 而对 TN 的去除率, 除第I周期浮床种植组与 CK 组间的差异不显著外, 沙基种植组和浮床种植 组的 TN 去除率均显著高于 $\mathrm{CK}$ 组; 在第I III和IV 周期, 沙基种植组的表现显著高于浮床种植组 $(P=4.72 \mathrm{E}-4 \sim$ 0.045). 结果表明, 与 CK 组相比, 在温带冬季气候条件下, 沙基种植和浮床种植组的水芹均表现为较高的 TP 和 TN 去除能力. 总体而言, 与浮床种植方式相比, 沙基种植方式其去除率更高. 而对于 COD 的去除率周期间 波动较大,浮床种植组对 COD 的去除率略高于沙基种植组且周期间更为稳定.
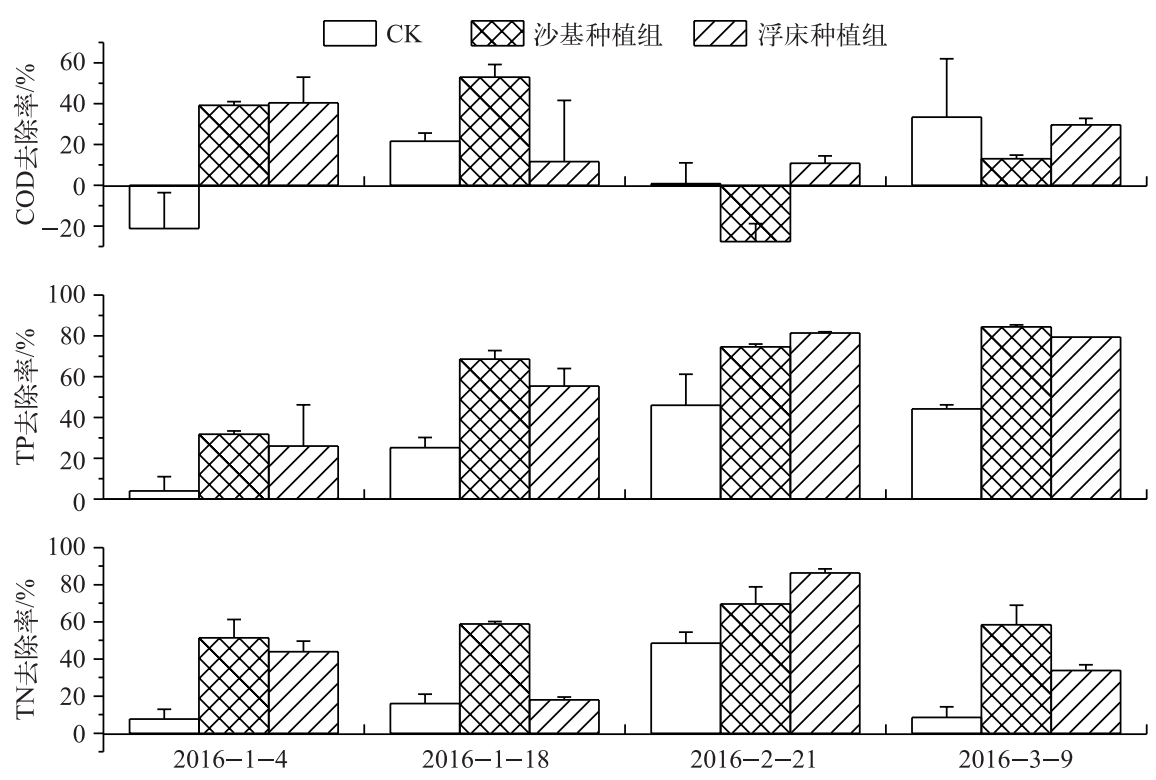

图 33 个实验组对水中营养物质 COD、TN 和 TP 的去除率

Fig.3 Removal efficiencies of COD, TN and TP in the three studied batches

\section{2 植物的生长状况}

2.2.1 植株高度 经过预培养后, 沙基种植组和浮床种植组地上植株高度分别为 28.44 和 $24.89 \mathrm{~cm}$, 而地下 部分高度分别为 16.22 和 $13.56 \mathrm{~cm}$ (图 4). 在随后的 I、III 和 IV 周期, 沙基种植组地上部分均显著高于浮床 种植组 ( $P=8.44 \mathrm{E}-14 \sim 0.001)$; 而根系部分, 沙基种植组在第 II 周期表现为略高于浮床种植组, 处理间差异 显著 $(P=0.001)$, 而在第 $I I I$ 和第 $\mathrm{IV}$ 周期显著低于浮床种植组 $(P=6.05 \mathrm{E}-9 \sim 1.95 \mathrm{E}-6)$. 表明, 沙基种植水生 植物的淹水状态可促进茎叶的伸长, 提高植株高度; 而浮床种植方式更有利于第二年温度回升过程中根的 快速伸长.

2.2.2 植株生物量 经过预处理阶段, 浮床种植组处理总生物量显著高于沙基种植组处理 $(P=4.83 \mathrm{E}-9)$, 到 第 I 周期, 浮床种植组处理的调落物迅速增加, 并显著高于于沙基种植组处理 $(P=3.83 \mathrm{E}-5)$, 到第 II 周期, 浮床种植组总生物量开始下降, 而沙基种植组总生物量仍然保持增加趋势, 到第 IV 周期末, 2 个处理间总生 物量差异不显著 (表 1). 在整个实验周期, 浮床种植组的根部生物量第 I 、II 周期一直高于沙基种植组处理 $(P=6.99 \mathrm{E}-7 \sim 0.028)$, 在可收集到调落物的周期 (第 I 、 II 和 III 周期), 浮床种植组的调落物生物量也一直 高于沙基种植组处理. 同时, 在温度降低的 II 、III 周期, 沙基种植组茎部生物量显著高于浮床种植组 $(P=$ 0.006 0.015). 结果表明, 浮床种植方式有利于植物总生物量的增加, 特别是根系生物量的增加, 同时其调 落物量也显著高于沙基种植方式, 沙基种植组有利于茎部生长; 但结合 2.1 节的结果表明, 浮床种植组处理 由于植物的调落物存在于浮床之上, 对水体造成的二次污染相对较轻.

\section{3 根系活性和泌氧能力}

水芹根系活性测定结果为, 在第 II 周期, 沙基种植组处理显著高于浮床种植组处理 $(P=0.038)$, 但进人 第 III 周期, 沙基种植组处理根系活性迅速下降, 沙基种植组处理显著低于浮床种植组处理 $(P=1.58 \mathrm{E}-4)$, 第 IV 周期, 沙基种植组处理根系活性迅速回升, 而浮床种植组处理则较前期略有下降, 沙基种植组显著高于浮 


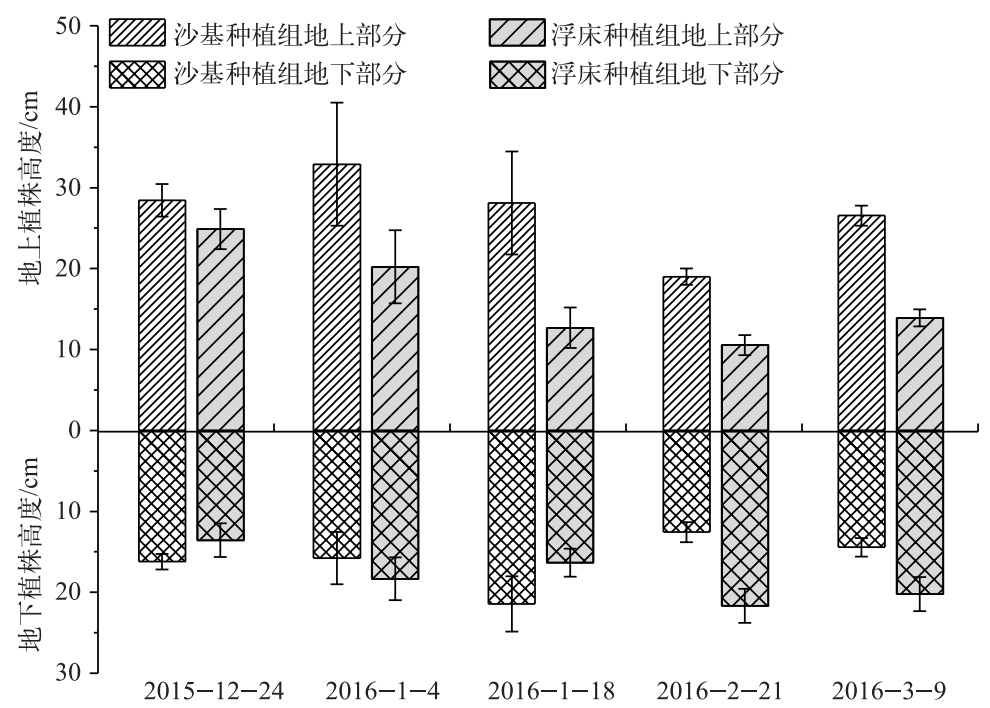

图 44 个阶段不同种植方式的水芹生长情况

Fig.4 The plant height of Oenanthe javanica using two planting methods during four periods

表 1 不同种植方式植株生物量及其分配 $\left(\mathrm{g} / \mathrm{m}^{2}\right)$

Tab.1 Dry biomass of Oenanthe javanica and the distribution using two planting methods

\begin{tabular}{lcccccc}
\hline 种植方式 & 部位 & $2015-12-24$ & $2016-1-4$ & $2016-1-18$ & $2016-2-21$ & $2016-3-9$ \\
\hline 沙基种植组 & 根部 & $10.26 \pm 3.67$ & $10.04 \pm 2.96$ & $22.35 \pm 8.06$ & $20.18 \pm 6.81$ & $14.08 \pm 3.42$ \\
& 茎部 & $17.58 \pm 1.16$ & $21.16 \pm 4.08$ & $19.12 \pm 6.50$ & $9.67 \pm 3.13$ & $12.65 \pm 3.85$ \\
& 叶部 & $10.84 \pm 1.00$ & $3.22 \pm 0.85$ & $3.14 \pm 2.12$ & $1.29 \pm 1.25$ & $4.46 \pm 1.31$ \\
& 调落部分 & $0 \pm 0$ & $5.54 \pm 2.22$ & $10.19 \pm 4.20$ & $4.75 \pm 2.97$ & $0 \pm 0$ \\
浮床种植组 & 总干重 & $38.68 \pm 4.85$ & $44.92 \pm 7.28$ & $54.80 \pm 17.60$ & $35.90 \pm 6.65$ & $31.19 \pm 7.30$ \\
& 根部 & $21.63 \pm 2.32$ & $11.08 \pm 3.27$ & $23.10 \pm 12.91$ & $24.56 \pm 6.64$ & $15.79 \pm 2.23$ \\
& 茎部 & $22.67 \pm 2.67$ & $9.16 \pm 3.61$ & $10.51 \pm 4.87$ & $6.19 \pm 2.24$ & $9.92 \pm 4.46$ \\
& 叶部 & $17.25 \pm 0.95$ & $1.77 \pm 1.14$ & $3.57 \pm 2.31$ & $2.01 \pm 1.27$ & $5.33 \pm 2.02$ \\
& 调落部分 & $0 \pm 0$ & $11.60 \pm 4.17$ & $15.90 \pm 13.93$ & $9.45 \pm 7.00$ & $0 \pm 0$ \\
& 总干重 & $61.55 \pm 3.65$ & $33.61 \pm 7.64$ & $53.08 \pm 28.88$ & $42.20 \pm 12.55$ & $31.03 \pm 4.68$ \\
\hline
\end{tabular}

床种植组处理 $(P=0.004)$. 根系泌氧能力与根系活力结果相似: 在第 I 周期, 沙基种植组处理显著高于浮床 种植组处理 $(P=0.013)$, 进人第 III 周期, 沙基种植组处理根系泌氧能力迅速下降, 沙基种植组处理低于浮床 种植组处理, 第 IV 周期, 沙基种植组泌氧能力迅速回升, 而浮床种植组处理则较前期迅速降低, 沙基种植组 显著高于浮床种植组处理 $(P=0.018$ ) (表 2). 结果表明, 相对于浮床种植, 传统的沙基种植法能使水芹根系 在温带冬季大部分时间内保持较高的活力和泌氧能力.

表 2 不同种植方式的水芹根系活力和根系径向泌氧

Tab.2 The radial oxygen loss and root activity of Oenanthe javanica using two planting methods

\begin{tabular}{lccccc}
\hline 类别 & 种植方式 & $2015-12-24$ & $2016-1-4$ & $2016-1-18$ & $2016-2-21$ \\
\hline 根系活力 $/(\mu \mathrm{g} /(\mathrm{g} \cdot \mathrm{h}))$ & 沙基种植组 & $99.71 \pm 13.07$ & $157.80 \pm 27.03$ & $39.84 \pm 2.98$ & $80.79 \pm 2.31$ \\
& 浮床种植组 & $59.18 \pm 28.71$ & $82.34 \pm 33.21$ & $68.02 \pm 1.89$ & $65.16 \pm 3.83$ \\
根系泌氧 $(\mu \mathrm{g} /(\mathrm{L} \cdot \mathrm{h} \cdot \mathrm{unit}))$ & 沙基种植组 & $533.33 \pm 51.32$ & $636.67 \pm 100.66$ & $400.00 \pm 121.24$ & $736.67 \pm 145.72$ \\
& 浮床种植组 & $200.00 \pm 79.25$ & $586.67 \pm 211.27$ & $620.00 \pm 164.62$ & $353.33 \pm 90.18$ \\
\hline
\end{tabular}




\section{3 讨论}

\section{1 温度影响植物生长}

温度是制约植物生长的重要环境因子 ${ }^{[16]}$, 水芹的生长与温度密切相关, $25^{\circ} \mathrm{C}$ 以下, 母茎开始萌芽生长, $15 \sim 20^{\circ} \mathrm{C}$ 生长最快, $5^{\circ} \mathrm{C}$ 以下停止生长, $-10^{\circ} \mathrm{C}$ 低温依然可以存活 ${ }^{[17]}$. 人工湿地中栽种的水生植物对人工污水 中营养物质的去除效果与植物生长的不同阶段和不同生长状态有关, 植物生长旺盛对人工污水的净化效果 也较好 ${ }^{[18-19]}$. 本实验中, 人工湿地中的植物采取沙基种植和浮床种植 2 种种植方式, 2 种湿地中植物的生长 情况直接影响着人工湿地对污水的净化效果. 第 $\mathrm{I}$ 、II 周期, 水体温度在 $2 \sim 10^{\circ} \mathrm{C}$ 之间波动, 水芹基本不生长. 实验中, 沙基种植的水芹经过预培养阶段之后,较快适应了水位胁迫, 表现在水芹根系中老根逐渐脱落的同 时, 新生很多根芽. 当嫩根开始生长, 根系活力、根系泌氧也表现良好. 同时, 沙基种植组营养物质去除率均 表现较好. 与之相反, 浮床种植组根系部分长度表现较好, 第 I 、II 周期, 沙基种植组地下部分长度低于浮床 种植组, 差异具有统计学意义 $(P=1.08 \mathrm{E}-7)$, 说明浮床种植法更有利于水芹根系部分的伸长生长. 第 III 周 期, 时间间隔 $33 \mathrm{~d}$, 空气温度出现 $0^{\circ} \mathrm{C}$ 以下, 人工湿地中的水体出现结冰现象. 记录显示, 表层冰块厚度在 $5 \mathrm{~cm}$ 以上,至完全化开,冰水混合物时间持续 8 10 d. 降温期间,沙基种植组水芹被冻在冰块中,地下根系 出现结冰现象. 浮床种植组情况则是, 水芹地上部分开始萎䔍调落, 只留少许嫩芽部位存活, 停止生长, 浮床 种植组的地下部分根系全部被冰封. 第 III 周期中期之后, 冰冻彻底溶化, 人工湿地水体温度升高至 10 $15^{\circ} \mathrm{C}$, 沙基种植组茎叶部分脱落腐烂现象严重, 在测定植物指标时清理出较多发黑脱落根系, 同时根系活力 没有恢复, 仅有 $39.84 \mu \mathrm{g} /(\mathrm{g} \cdot \mathrm{h})$. 第 IV 周期, 温度在 $3.79 \sim 15.95^{\circ} \mathrm{C}$ 之间, 适宜水芹生长, 沙基种植组和浮床种 植组均没有调落物产生.

\section{2 有机物去除效果}

污水中的有机物分为颗粒状物质和溶解性物质, 颗粒物质容易被人工湿地基质截留或沉积于底部, 溶 解性物质通过微生物作用去除 ${ }^{[20]}$. 本实验中, CK 组在第 I 周期 COD 增加 $21.3 \%$. 同周期, CK 组水体叶绿素 $\mathrm{a}$ 浓度为 $341.8 \mu \mathrm{g} / \mathrm{L}$, 显著高于沙基种植组处理 $(71.9 \mu \mathrm{g} / \mathrm{L}, P=3.1 \mathrm{E}-7)$ 和浮床种植组处理 $(107.93 \mu \mathrm{g} / \mathrm{L}$, $P=2.7 \mathrm{E}-7)$. 当温度、光照、含盐量和水体富营养程度等较适宜藻类生长, 且不存在其他利用营养物质的竞 争因素时, 水体中易暴发藻类 ${ }^{[21-25]}$ 水体呈现浅绿色, 并且清晨有微小气泡冒出水面, 说明当时温度适宜藻类 生长, 固定了空气中的 $\mathrm{CO}_{2}$, 形成了有机质, 增加了水体中的 $\mathrm{COD}$. 而在本实验中, 沙基种植的水芹在第 $\mathrm{I}$ 和 II 周期对 COD 有较好的去除率. 栽种植物的人工湿地则较好地利用了水体中的营养物质,阻止了藻类的暴 发. 第 III 周期 $33 \mathrm{~d}$, 沙基种植组 COD 去除率为负值, 原因是人工湿地中水芹在温度较低时结冰, 温度升高后 调落物在人工湿地中脱落腐烂, 致使水体中 COD 增加 ${ }^{[26-27]}$. 浮床植物组在净化过程中, 呈现出先降低后升 高的趋势, 4 个周期 COD 去除率依次为 $40.42 \% 、 11.67 \% 、 10.83 \%$ 和 $29.58 \%$. 结果表明, 冬季人工湿地中种植 水芹, 可以有效去除水体中的 COD. 温度低于 $0^{\circ} \mathrm{C}$ 时, 水芹调落物分解, 增加了水体中的 $\mathrm{COD}$; 与沙基培养法 相比,浮床种植法尽管其调落物增加,但浮床的存在阻止其进人水体, 可降低其对水体的二次污染.

\section{3 根系泌氧影响总氮去除}

潜流湿地中 $\mathrm{pH}$ 值一般在 7 8 之间, 非离子态氨挥发量很少 ${ }^{[28]}$, 湿地植物吸收氨氮, 去除水体中的氮. 植物的净吸收和储存相对很少,一般不会超过总去除率的 $15 \%$,一般认为微生物反硝化脱氮产生氮气和氮 氧化物被认为是主要的脱氮机制. 研究表明, 人工湿地中的除氮途径白天以好氧的硝化作用为主,夜间以厌 氧、缺氧的反硝化作用为主 ${ }^{[29-30]}$. 植物根系泌氧是在构造湿地中形成根际氧化一还原微生态系统的核心要 素, 为好氧、厌氧微生物提供了良好生存代谢环境, 湿地植物根际部分是有机物降解、 $N 、 P$ 循环及相关活动 最为强烈的场所, 同时, 植物根系泌氧的强弱与植物的生长以及污染物的去除效果密切相关 ${ }^{[29,31-33]}$. 由于水 体氧气浓度的限制, 好氧微生物主要附着在水芹根际. 硝化能力是人工湿地污水脱氮系统总效率的限制因 子 ${ }^{[34-35]}$. 实验中, 采用沙基法种植的水芹在温带冬季大部时间内表现更高的泌氧能力和根系活力, 从而有利 于在根际形成好氧条件, 与远离根际的厌氧区组合,保证硝化一反硝化过程的进行,使得传统的沙基法能够 保持较高的氮去除能力. 


\section{4 结论}

本文针对冬季人工湿地水体净化能力严重不足的问题, 在温带冬季以耐寒水生植物水芹为供试材料, 研究了传统的沙基法和浮床法, 对人工污水净化的效果、植物生长状况以及根系泌氧能力和活力的影响. 结 果表明:

1) 与 CK 组相比,2 种种植方式下的人工湿地均表现为较强的 TP 和 TN 去除能力, 总体而言, 与浮床种 植方式相比, 沙基种植方式其去除率更高. 而对于 COD 的去除率周期间波动较大, 浮床种植组对 COD 的去 除率略高于沙基种植组且周期间更为稳定.

2) 2 种种植方式下, 水芹均可安全度过温带寒冷的冬季, 与沙基种植法相比, 浮床种植方式更有利于植 物总生物量的增加, 特别是根系生物量的增加,但同时其凋落物量也显著高于沙基种植方式.

3 ) 相对于浮床种植, 传统的沙基种植法能使水芹根系在温带冬季气候大部分时间内保持较高的活力和 泌氧能力, 从而有利于 TN 的去除.

因此, 考虑到建设成本, 在两种种植方式均可选择的条件下, 可优选传统的沙基(或底泥)种植方式; 对 深水等不能采用沙基(或底泥)种植方式的区域, 可选用浮床种植的方式, 也能保证耐寒水生植物的度过温 带冬季和保持较高的净化能力.

\section{5 参考文献}

[ 1 ] Zhu L, Li Z, Ketola T. Biomass accumulations and nutrient uptake of plants cultivated on artificial floating beds in China's rural area. Ecological Engineering, 2011, 37(10): 1460-1466.

[ 2 ] Li XN, Song HL, Wei L et al. An integrated ecological floating-bed employing plant, freshwater clam and biofilm carrier for purification of eutrophic water. Ecological Engineering, 2010, 36(4) : 382-390.

[ 3 ] Wu Q, Hu Y, Li S et al. Microbial mechanisms of using enhanced ecological floating beds for eutrophic water improvement. Bioresource Technology, 2016, 211:451-456.

[ 4 ] Zhao XJ, Li XL Tao L et al. Study on variation of enzyme activity in ceramsite floating bed and its relationship with removal of pollutants. Freshwater Fisheries, 2015, 45(6): 66-69.

[ 5 ] Yang J, Zhang L, Liu W et al. Purifying effects of ecological floating bed for waterfowl breeding sewage. Journal of Zhongkai University of Agriculture \& Engineering, 2016, 29(1) : 30-33.

[ 6 ] Zhou X, Wang G. Nutrient concentration variations during Oenanthe javanica growth and decay in the ecological floating bed system. Journal of Environmental Sciences, 2010, 22(11) : 1710-1717.

[ 7 ] Annelies VDM. Screening of different plant species for the application on constructed floating wetlands. 3rd Symposium on Wetland Pollutant Dynamics and Control (WETPOL 2009), 2009.

[ 8 ] He HZ, Yu J, Li YJ et al. Studies on mediation of eutrophic water using artificial floating-beds system established with three wetland plants. Journal of South China Agricultural University, 2011, 32(2): 16-20.

[ 9 ] Zhang Y, Li X, Xu Y et al. Removal of nitrogen and phosphorus by eight plants of float bed constructed wetland. Environmental Pollution \& Control, 2012, 34(8): 49-52.

[10] Xu GD, Hu JZ, Gang TML et al. Effect of the structure of composite ecological floating bed on eutrophic pollutants removal in water. Advanced Materials Research, 2014, 1073-1076:755-758.

[11] Xu GJ, Duan DX, Du XH et al. Aquaculture waste water treatment by an enhanced ecological floating bed based on synergistic effect. Journal of Dalian Ocean University, 2015, 30(1) : 62-67.

[12] Zhang Z, Yang Z, Huang K. Improved designs of ecological floating-bed. International Conference on Environmental Technology and Knowledge Transfer, 2010: 829-831.

[13] Turk MT, Turk RT, Yasar F. Changes in micronutrients, dry weight and plant growth of soybean (Glycine max L. Merrill) cultivars under salt stress. African Journal of Biotechnology, 2008, 7(11) :1650-1654.

[14] Li Zhaojun, Xie Xiaoyu, Zhang Shuqing et al. Negative effects of oxytetracycline on wheat (Triticum aestivum L.) growth, root activity, photosynthesis, and chlorophyll contents. Agricultural Sciences in China, 2011, 10(10): 1545-1553.

[15] Li Yilin. Relationship among rice root aerechyma, root radial oxygen loss and rhizosphere nitrification. Acta Ecologica Sini- 
$c a, 2012,32(7)$ : 2066-2074. [李奕林. 水稻根系通气组织与根系泌氧及根际硝化作用的关系. 生态学报, 2012, 32( 7) : 2066-2074.]

[16] Osland MJ, Enwright N, Day RH et al. Winter climate change and coastal wetland foundation species: Salt marshes vs. mangrove forests in the southeastern United States. Global Change Biology, 2013, 19( 5 ) : 1482-1494.

[17] Li L. Experiment on natural overwintering and water clearing of water cress planted on floating bed in eutrophicated water body. Water Pollution and Treatment, 2015, 3(1): 13-18.

[18] Hernández-Crespo C, Oliver N, Bixquert J et al. Comparison of three plants in a surface flow constructed wetland treating eutrophic water in a Mediterranean climate. Hydrobiologia, 2016, 774(1) : 183-192.

[19] Alldred M, Baines SB. Effects of wetland plants on denitrification rates: A meta-analysis. Ecological Applications, 2016, 26(3) : 676-685.

[20] Li C, Wu S, Dong R. Dynamics of organic matter, nitrogen and phosphorus removal and their interactions in a tidal operated constructed wetland. Journal of Environmental Management, 2015, 151: 310-316.

[21] Liu Bo, Cui Lifeng, Liu Zaiwen. Correlation between chlorophyll a and algal density of surface water in urban of Beijing. Environmental Science \& Technology, 2008, 31(8): 29-33. [刘波, 崔莉凤, 刘载文. 北京市城区地表水体叶绿素 a 与藻密度相关性研究. 环境科学与技术, 2008, 31(8) : 29-33.]

[22] Gao L, Wei Q, Fu F et al. Influence of outbreak of macro-algal blooms on phosphorus release from the sediments in Swan Lake Wetland, China. Plant Biosystems, 2013, 147(4) : 1175-1183.

[23] Wei Quan, Shao Xuelin, Gao Li. Effects of macro-algal blooms on phosphorus concentrations in water and sediments of Rongcheng Swan Lake. Ecology and Environment, 2014, (1) : 139-144. [魏权, 邵雪琳, 高丽. 绿潮藻类暴发对天鹅 湖水体和沉积物磷含量的影响. 生态环境学报, 2014, (1): 139-144.]

[24] Xu N, Huang B, Hu Z et al. Effects of temperature, salinity, and irradiance on the growth of harmful algal bloom species Phaeocystis globosa, scherffel (Prymnesiophyceae) isolated from the South China Sea. Chinese Journal of Oceanology \& Limnology, 2017, 35(3) : 557-565.

[25] Tan S, Zhou J, Zhu X et al. An association network analysis among microeukaryotes and bacterioplankton reveals algal bloom dynamics. Journal of Phycology, 2015, 51(1) : 120-132.

[26] Zhu H, Yan B, Xu Y et al. Removal of nitrogen and COD in horizontal subsurface flow constructed wetlands under different influent $\mathrm{C} / \mathrm{N}$ ratios. Ecological Engineering, 2014, 63: 58-63.

[27] Taylor CR, Hook PB, Stein OR et al. Seasonal effects of 19 plant species on COD removal in subsurface treatment wetland microcosms. Ecological Engineering, 2011, 37(5) : 703-710.

[28] Jayaweera GR, Mikkelsen DS. Assessment of ammonia volatilization from flooded soil systems. Advances in Agronomy, 1991, 45: 303-356.

[29] Lin Jianhua, Yang Yang, Li Li et al. Characteristics of growth and radial oxygen loss of eight wetland plant. J Lake Sci, 2015, 27 (6) : 1042-1048. DOI: 10.18307/2015.0608. [林剑华, 杨扬, 李丽等. 8 种湿地植物的生长状况及泌氧能 力. 湖泊科学, $2015,27(6): 1042-1048$. ]

[ 30] Chen Mengyin, Zhu Wei, Dong Chan. Nitrogen forms in integrated vertical-flow on man-made wetland based on the diurnal fluctuations of oxygen release in cattail roots. J Lake Sci, 2013, 25(3) : 392-397. DOI : 10.18307/2013.0313. [ 陈梦银, 朱伟, 董婵. 基于植物昼夜释氧变化规律的复合垂直流人工湿地氮形态. 湖泊科学, 2013, 25(3): 392-397.]

[31] Cheng XY, Wang M, Zhang CF et al. Relationships between plant photosynthesis, radial oxygen loss and nutrient removal in constructed wetland microcosms. Biochemical Systematics \& Ecology, 2014, 54(Complete) : 299-306.

[32] Sasikala S, Tanaka N, Wah HSYW et al. Effects of water level fluctuation on radial oxygen loss, root porosity, and nitrogen removal in subsurface vertical flow wetland mesocosms. Ecological Engineering, 2009, 35(3) : 410-417.

[33] Lai WL, Zhang Y, Chen ZH. Radial oxygen loss, photosynthesis, and nutrient removal of 35 wetland plants. Ecological Engineering, 2012, 39(7) : 24-30.

[34] Wang X, Tian Y, Zhao X et al. Effects of aeration position on organics, nitrogen and phosphorus removal in combined oxidation pond-constructed wetland systems. Bioresource Technology, 2015, 198: 7-15.

[35] Lu Shaoyong, Jin Xiangcan, Yu Gang. Nitrogen removal mechanism of constructed wetland. Acta Ecologica Sinica, 2006, 26(8) : 2670-2677. [卢少勇, 金相灿, 余刚. 人工湿地的氮去除机理. 生态学报, 2006, 26(8) : 2670-2677.] 